\title{
Sublobar resection for lung cancer
}

\author{
R. Rami-Porta* and M. Tsuboi ${ }^{\#}$
}

\begin{abstract}
Sublobar resection for small lung cancers has been debated frequently and is still a controversial issue. The only randomised trial comparing lobectomy with sublobar resections found a significantly higher recurrence rate for the latter, but failed to show significant differences in survival, although survival was better for the lobectomy group. One meta-analysis and several nonrandomised comparisons have confirmed these results. In general, lobectomy and sublobar resections have similar 5-yr survival rates. Local recurrence after wedge resection is higher than after segmentectomy. However, for patients aged $>71$ yrs, lobectomy and wedge resection are associated with similar survival. For tumours of $\leqslant 2 \mathrm{~cm}$, segmentectomy is equivalent to lobectomy, but survival after segmentectomy is worse if performed for larger tumours. For both segmentectomy and wedge resection, tumour margins should be $\geqslant 1 \mathrm{~cm}$ wide to avoid recurrence. For pure bronchioloalveolar carcinoma of $\leqslant 2 \mathrm{~cm}$, diagnosed intraoperatively with certainty, sublobar resection seems equivalent to lobectomy, and because there is no nodal involvement, systematic nodal dissection may not be necessary. In case of doubt, however, lobectomy with systematic nodal dissection will ensure complete resection and adequate staging. More randomised trials are needed to confirm all these issues.
\end{abstract}

KEYWORDS: Bronchioloalveolar carcinoma, lobectomy, nonsmall cell lung cancer, segmentectomy, sublobar resection, wedge resection

RAHAM and SINGER [1] are credited with having performed the first pneumonectomy for lung cancer in 1933 and, for some years, it was thought that the removal of the whole lung was the standard operation for lung cancer. In the 1950s and 1960s, CAHAN and co-workers [2, 3] standardised pneumonectomy and lobectomy with mediastinal lymph node dissection very much as they are still performed today. However, ever since patients with lung cancer have undergone surgical treatment, thoracic surgeons have been faced with the impossibility of performing the intended lung resection in patients whose lung function would not allow such a parenchymal loss. Sublobar resections, both segmentectomies and wedge resections, were common in the treatment of tuberculosis [4], and it was just a matter of time before such an operation found its way into oncological surgery. In 1973, JENSIK et al. [5] reported their first experience with 69 patients, which was expanded in 1979 with the addition of 99 patients, for a total of 168 [6]. Their decision to perform segmentectomy was not functional, but anatomical: peripheral tumours with no lobar or mediastinal nodal involvement. The 5-yr survival rate of their series of patients with tumour (T) 1 and T2 tumours was $53 \%$, with a $2 \%$ post-operative mortality rate. Of their patients, $45(27 \%)$ died with recurrence: 29 (17\%) distant and 16 (10\%) local. WeISBERG et al. [7] reproduced the same results 14 yrs later, with a series of 170 patients with stage I lung cancer who underwent sublobar resections (segmentectomy 58, wedge resection 97 and unspecified 15). Their 5-yr disease-free survival was $54.7 \%$, and their postoperative mortality $3.5 \%$. Local recurrence with or without metastases was observed in 22 (14.1\%) patients. Between these two series, PASTORINO et al. [8] published a retrospective comparison of lobectomy and sublobar resection, with similar results and with no significant differences in 5-yr survival and recurrences between the two groups. Global 5yr survival for sublobar resections and lobectomies was $55 \%$ and $49 \%$, respectively. For pathological (p)T1 and pT2 tumours, 5 -yr survival was $73 \%$ and $35 \%$, respectively, for sublobar resections; and 55\% and $46 \%$, respectively, for lobectomies. The recurrence rate was $36 \%$ for sublobar resections and $38 \%$ for lobectomies.

Previous article in this series: No. 1: De Wever W, Stroobants S, Coolen J, Verschakelen JA. Integrated PET/CT in the staging of nonsmall cell lung cancer: technical aspects and clinical integration. Eur Respir J 2009; 33: 201-212.

AFFILIATIONS

${ }^{*}$ Thoracic Surgery Service, Hospital Mutua de Terrassa, University of Barcelona, Terrassa, Barcelona, Spain.

\#Dept of Thoracic Surgery, Tokyo Medical University, Tokyo, Japan.

CORRESPONDENCE

R. Rami-Porta

Thoracic Surgery Service

Hospital Mutua de Terrassa

Plaza Dr. Robert 5

08221 Terrassa

Barcelona

Spain

Fax: 34937365059

E-mail: rramip@terra.es

Received:

July 022008

Accepted:

August 012008

STATEMENT OF INTEREST None declared. 
Despite these relatively good results, sublobar resection for lung cancer has been, and still is, a controversial issue. The only randomised clinical trial conducted to date [9] not only failed to clarify the controversy, it raised new ones because of the mixture of wedge resections and segmentectomies, and the loss to follow-up of some patients [10]. Sublobar resections were associated with a significant increase in locoregional recurrence compared with lobectomies, but cancer-related death rates and overall death rates did not show significant differences, although they were higher in the sublobar resection group [11]. Because of the increased risk of recurrence in sublobar resections, lobectomy was established as the minimal acceptable resection for lung cancer, while sublobar resections were considered a compromise solution for those patients who could not undergo lobectomy. A recent meta-analysis on survival following lobectomy and limited resection for stage I lung cancer confirmed the results of the randomised trial: there were no statistically significant differences between the two groups, but there was a small benefit in the lobectomy group. However, there was some interstudy heterogeneity that suggests that the results should be interpreted with caution [12]. At the same time, the routine use of computed tomography (CT) in clinical practice and in some screening programmes increased the number of small peripheral lung cancers, both in the form of solid or partly solid lesions, and pure bronchioloalveolar carcinomas as ground-glass opacities (GGOs), for which a lobectomy seems excessive. WATANABE et al. [13] reported that the rate of lung cancer $\leqslant 2 \mathrm{~cm}$ in diameter rose from $4.3 \%$ when CT was not used to $11 \%$ after introducing CT in their clinical practice, and to $17 \%$ after the introduction of high-resolution CT (HRCT); the equivalent figures for cancers $\leqslant 1 \mathrm{~cm}$ were $0.4 \%, 1 \%$ and $1.5 \%$, respectively. This represents a four-fold increase in the number of tumours of both sizes. Additionally, $78-100 \%$ of lung cancers identified in screening programmes using lowdose spiral CT are in stage I [14].

In this scenario of increasing numbers of patients with small tumours and the possibility of second-lung primaries in longterm survivors, for whom the preservation of lung function is important, there has been an increasing interest in sublobar resections for small lung cancers. This has been shown in several revisions that have extensively addressed the issue in the past few years [15-18]. The purpose of the present review is to summarise the available evidence on sublobar resections for nonsmall cell lung cancer, making a distinction between solid and partly solid lesions, and bronchioloalveolar carcinoma, because their degree of invasiveness differs.

\section{TYPES OF SUBLOBAR RESECTION}

Lung resections that comprise less than a lobe are called sublobar, sublobular, conservative, lesser, substandard or limited resections. The term sublobar will be used throughout the present review. It includes wedge resections and segmentectomies. A wedge resection is the removal of part of the lung regardless of its anatomical boundaries. It can be part of one segment or a portion of lung parenchyma comprising two or more neighbouring segments. It is also called atypical resection (fig. 1). A segmentectomy implies the removal of an anatomical unit (fig. 2). It requires the identification and dissection of the segmental bronchus and artery, which are sutured and

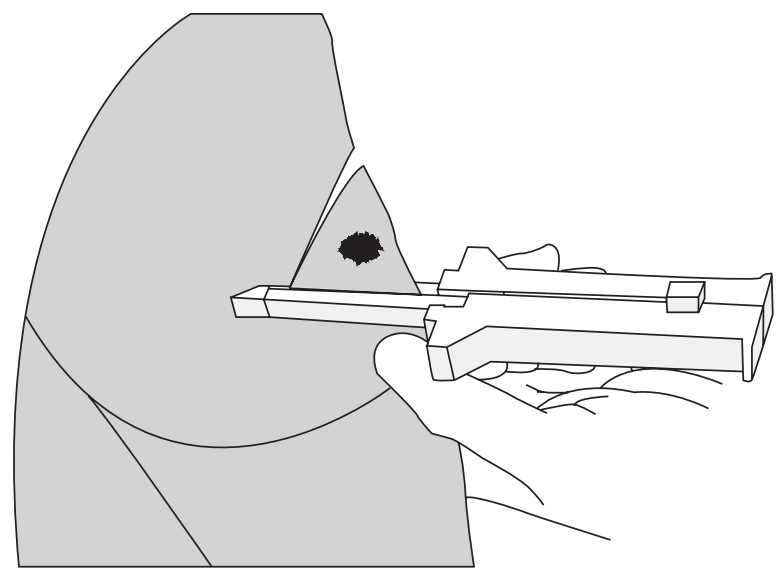

FIGURE 1. Wedge resection. Reproduced from [19], with permission from the publisher.

ligated, respectively, and the identification of the common vein of the two adjacent segments, which must be respected. The tributary veins from the resected segment are ligated only as they appear in the intersegmental plane. A segmentectomy is an anatomical lung resection together with lobectomy, bilobectomy and pneumonectomy. An extended segmentectomy, as defined by OKADA et al. [20], is a resection of both the affected

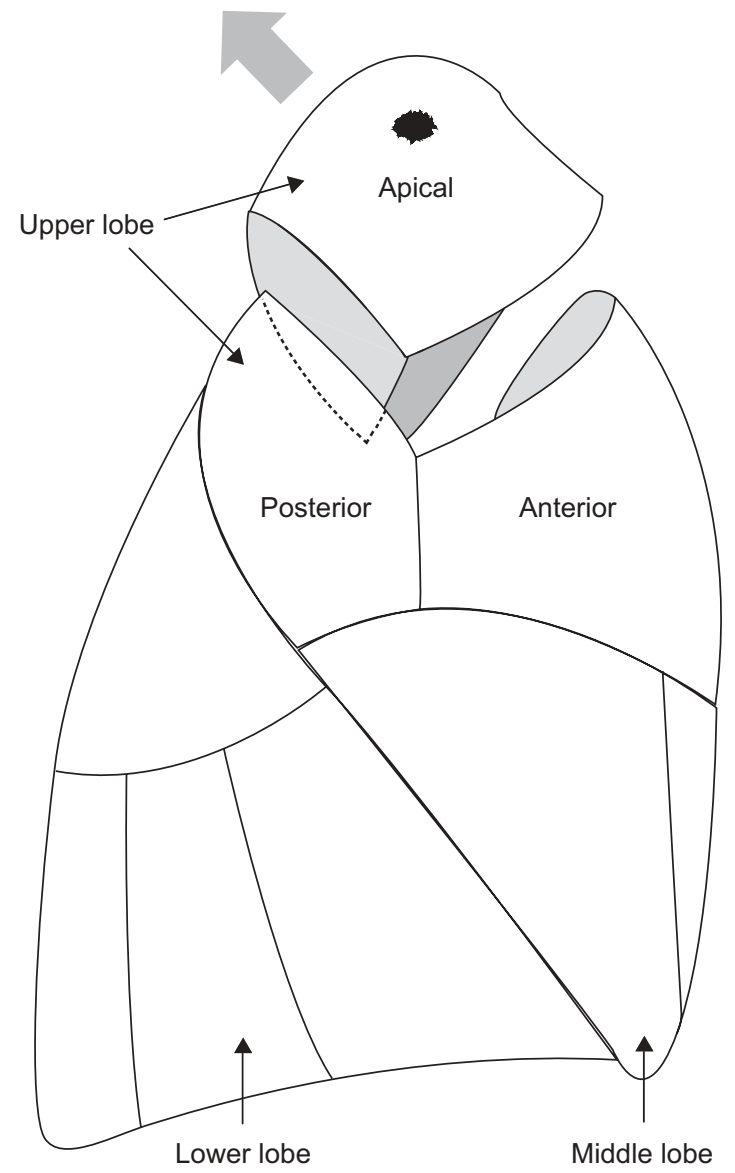

FIGURE 2. Segmentectomy. Reproduced from [19], with permission from the publisher. 
segment and adjacent subsegments plus exploration of mediastinal and hilar lymph nodes, which are examined pathologically as intra-operative frozen sections to confirm pathological node $(\mathrm{N}) 0$ status. In sleeve segmentectomies, the segmental bronchus is not incised at its origin, but it is removed with part of the lobar bronchus, which is then reconstructed with an end-to-end anastomosis. This is indicated when the tumour is too close to the origin of the segmental bronchus, in order to avoid a lobectomy [21]. Sublobar resections can be performed as open or videothoracoscopic procedures [22, 23]; the latter has been found to reduce hospital stay when compared with open segmentectomy [24].

\section{SUBLOBAR RESECTIONS FOR SMALL SOLID AND PARTLY SOLID PERIPHERAL TUMOURS \\ Indications}

Table 1 shows the most relevant data from 20 studies comparing lobectomy with sublobar resection [8, 20, 25-42]. All but three were retrospective: one was a prospective but nonrandomised study [28] and two were prospective observational studies $[20,34]$. In most studies, sublobar resections were indicated in patients with poor lung function, cardiac comorbidity, old age or previous lung surgery. However, in six studies from five different institutions, sublobar resections were intentional in patients who could otherwise tolerate a lobectomy [20, 25, 28, 32, 37, 41]. Most studies were limited to patients with stage I tumours, but three also included higherstage tumours [30, 34, 40].

\section{Survival and recurrence}

The 5-yr survival rates of lobectomy and sublobar resection were equivalent, except in six studies [25, 27, 35, 36, 40, 42]. WARREN et al. [25] compared the survival of 103 patients who had undergone lobectomy with the survival of 66 patients who had undergone segmentectomy: 5-yr survival was significantly better for those who had undergone lobectomy $(65 \%$ versus $45 \%)$. However, for those patients with tumours $\leqslant 2 \mathrm{~cm}$ or less, the two resections were associated with similar survival. Local/regional recurrence was significantly higher after segmentectomy $(22.7 \%$ versus $4.9 \%)$.

MiLLER et al. [27] reported on 100 patients with nonsmall cell lung cancer of $\leqslant 1 \mathrm{~cm}$ in diameter who had undergone lung resection; in 94 of them, mediastinal lymph node dissection had been performed. A total of 75 patients had undergone lobectomy or bilobectomy, 12 had undergone segmentectomy and 13 had undergone wedge resection. Their overall 5-yr survival rates were $71 \%, 57 \%$ and $27 \%(p=0.03)$, respectively. Seven patients in the series had lymph node metastasis, and the overall (43\%) and lung cancer-related (64\%) 5-yr survival rates of these patients were significantly lower than those for patients without nodal involvement: $66 \%$ and $87 \%$, respectively. In the study of MiLLER et al. [27], the overall recurrence rate was not statistically different in patients who had undergone lobectomy and sublobar resection, but when overall recurrence was analysed according to type of resection, wedge resection was associated with a significantly higher recurrence rate $(38.5 \%)$ compared with lobectomy (14.7\%) and segmentectomy $(16.7 \%)$. Although significant differences could not be found in local recurrence rates among the three groups, that for wedge resection $(30.8 \%)$ was much higher than those for lobectomy $(13.3 \%)$ and segmentectomy $(8.3 \%)$. Based on their results, MILLER et al. [27] recommended lobectomy with mediastinal lymph node dissection even for these small tumours.

In the series of EL-SHERIF et al. [35], both stage IA and IB tumours were included. Lobectomy was performed in 577 patients, and sublobar resection in 207 (122 wedge resections and 85 segmentectomies). The overall 5-yr survival rate was significantly better for lobectomy (54\%) than for sublobar resection (40\%), but when survival was analysed according to stage, the differences were maintained in patients with stage IB tumours only. Survival rates for patients with stage IA tumours were similar for both types of resection. However, when adjusted for age and number of lymph nodes removed at lymphadenectomy, sublobar resection had no adverse effect in patients with stage IB tumours. Overall recurrence was similar in both groups, but the local recurrence rate was significantly higher for sublobar resections (7.2\% versus $4.2 \%)$.

The series of GARZON et al. [36] included 25 patients with poor lung function who underwent either video-assisted thoracic surgery (VATS) lobectomy (13 patients) or VATS wedge resection (12 patients). Follow-up was very short (median 15.1 months), but within 2 yrs after the operation, five patients had died, four of them from cancer. All were in the wedge resection group, which was the only factor significantly associated with poorer survival. However, there were no differences in post-operative complications between both groups.

OKUMURA et al. [40] compared a series of 1,241 patients who had undergone lobectomy with 144 patients who had undergone segmentectomy. Six patients who had undergone segmentectomy had large cell carcinoma, of whom five died within 5 yrs after the operation. Consequently, this histological type was considered especially unsuited for this type of resection. Among patients with pT1N0-metastasis(M)0 tumours of $\leqslant 2 \mathrm{~cm}$ diameter who had undergone lobectomy, 5- and 10-yr survival rates, excluding large cell carcinomas, were $81 \%$ and $64 \%$, respectively; these rates were not statistically different from those for patients who underwent segmentectomy $(83 \%$ and $83 \%$, respectively). However, 5- and $10-y r$ survival rates for those patients with pT1N0M0 tumours $>2 \mathrm{~cm}$ in diameter were significantly better after lobectomy $(78 \%$ and $60 \%$, respectively) than after segmentectomy $(58 \%$ and $58 \%$, respectively; $\mathrm{p}=0.057$ ). Additionally, among patients undergoing segmentectomy, there was a significant progressive degradation of survival as tumour size increased. The 10-yr survival rates of patients with tumours $<1 \mathrm{~cm}, 1.1-2.0 \mathrm{~cm}, 2.1-3.0 \mathrm{~cm}$ and $3.1-$ $4.0 \mathrm{~cm}$ in diameter were $92 \%, 71 \%, 47 \%$, and $34 \%$, respectively $(\mathrm{p}=0.0015)$, with no 10-yr survivors among those with tumours $>4 \mathrm{~cm}$. Other than tumour size, nodal involvement, pleural invasion and histological type were found to have prognostic value in multivariate analysis.

Finally, in the series of SIENEL et al. [42], the cancer-related 5-yr survival rate for 150 patients who had undergone lobectomy was $83 \%$, which was significantly higher than the $67 \%$ found in 47 patients who had undergone segmentectomy. However, again, when patients with tumours of $\leqslant 2 \mathrm{~cm}$ in diameter were considered, survival differences were not statistically significant. Local recurrence was significantly higher in patients who 
TABLE 1 Retrospective (RC) and prospective nonrandomised comparison (PC) between lobectomy and sublobar resection

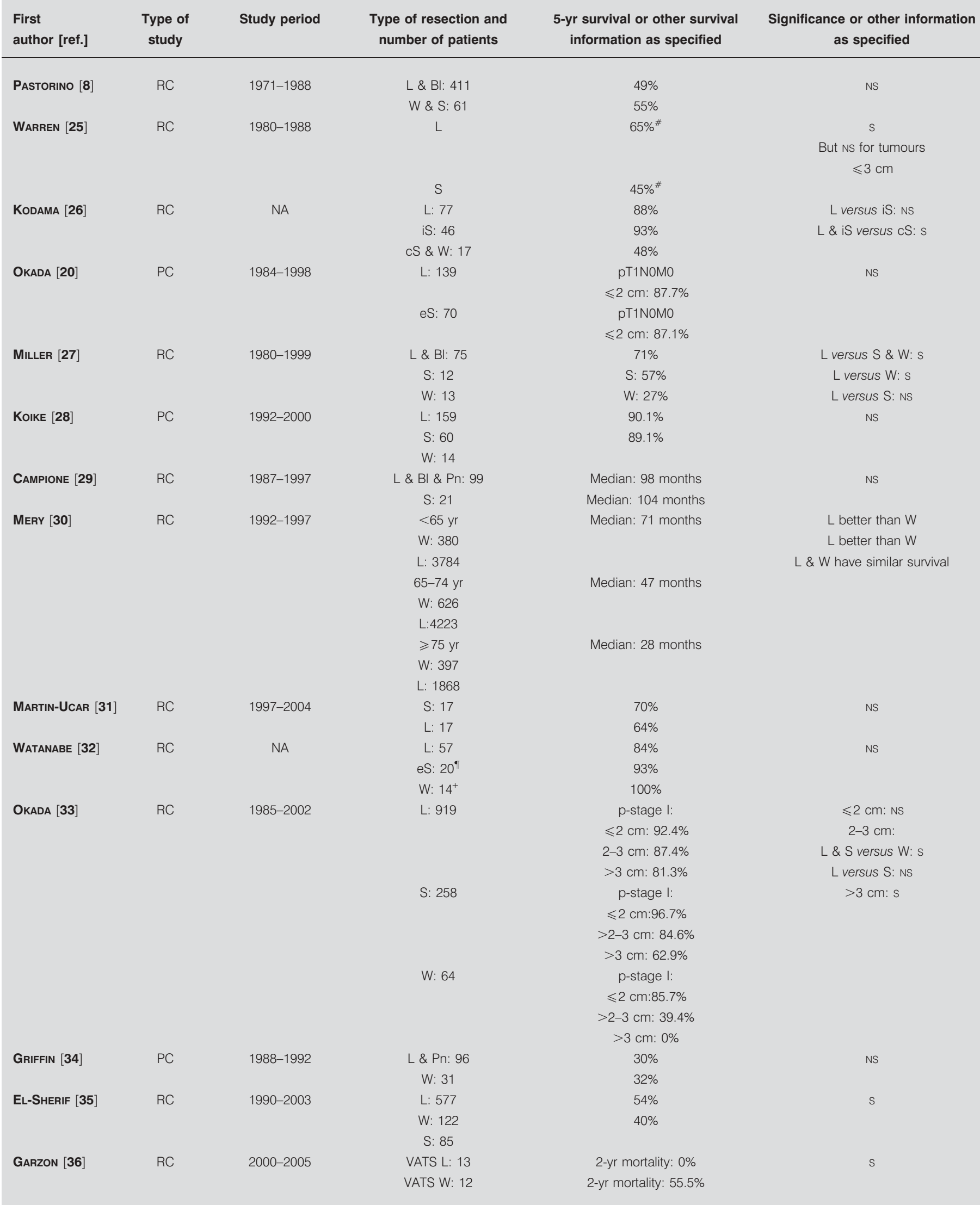




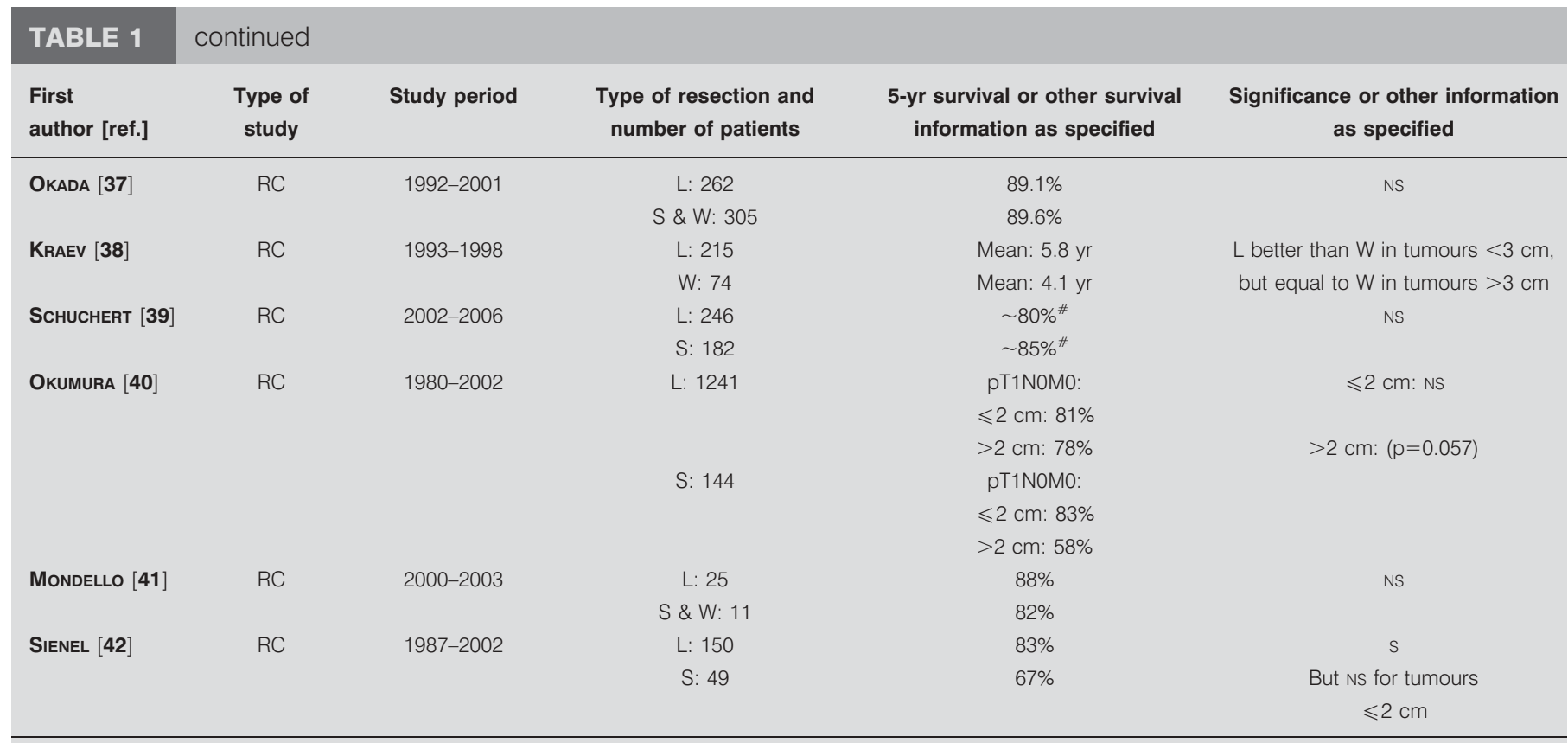

L: lobectomy; BI: bilobectomy; W: wedge resection; S: segmentectomy; NS: nonsignificant; NA: not available; iS: intentional segmentectomy; cS: compromised segmentectomy; s: significant; p: pathological; T: tumour; N: node; M: metastasis; eS: extended segmentectomy; Pn: pneumonectomy; VATS: video-assisted thoracic surgery. " : calculated from published survival graphs; ": non-Noguchi type A and $\mathrm{B} ;{ }^{+}$: bronchioloalveolar carcinoma, Noguchi type A and B.

had undergone segmentectomy, both in the group of patients as a whole and among those with smaller tumours.

\section{Tumour size}

The 2-cm landmark is consistently found in other studies. OKADA et al. [20] reported that extended segmentectomy was an alternative to lobectomy in patients with clinical (c)T1N0M0 tumours of $\leqslant 2 \mathrm{~cm}$ in diameter. Their 5-yr survival rates after extended segmentectomy and after lobectomy were $87.3 \%$ and $77.7 \%$, respectively $(p=0.1644)$. The 5 -yr survival rates of their pT1N0M0 counterparts were $87.1 \%$ for extended segmentectomy and $87.8 \%$ for lobectomy $(\mathrm{p}=0.8008)$. WARREN et al. [25], KOIKE et al. [28], WATANABE et al. [32] and SiENEL et al. [42] reported similar results in this selective group of patients with small T1 tumours.

\section{Age}

Patient age also seems to play a role in the outcome of sublobar resections. MERY et al. [30] studied this issue in the population of patients registered in the Surveillance, Epidemiology, and End Results database of the National Institutes of Health (Bethesda, MD, USA), and compared the results of lobectomy, pneumonectomy and wedge resection in patients aged $<65$ yrs, patients aged $65-74$ yrs of age and patients aged $\geqslant 75$ yrs. Lobectomy conferred significantly better survival in patients of the first two age groups, but in those aged $\geqslant 75 \mathrm{yrs}$, both lobectomy and wedge resection had similar survival. Further analysis of the data showed that the benefit of lobectomy was lost in patients aged $>71$ yrs.

\section{Segmentectomy versus wedge resection}

Two reports present retrospective comparisons of segmentectomy and wedge resection $[43,44]$. The report by EL-SHERIF et al. [43] focuses on the relationship between resection margin and local recurrence in patients with stage I nonsmall cell lung cancer who underwent either segmentectomy or wedge resection. In the group of patients who underwent segmentectomy, there were more resections with resection margins $>1 \mathrm{~cm}$. Local recurrence was significantly higher when resection margin was $<1 \mathrm{~cm}(14.6 \%)$ than when it was $\geqslant 1 \mathrm{~cm}(7.5 \%)$. Wedge resections had, therefore, narrower resection margins and were associated with higher local recurrence. In the series of EL-SHERIF et al. [43], resection margins had no impact on regional or distant recurrence. In the study of SIENEL et al. [44], 56 patients underwent segmentectomy with systematic nodal dissection and 31 underwent wedge resection with selective nodal sampling at the surgeon's discretion for stage I nonsmall cell lung cancer. Sublobar resections were indicated because of cardiopulmonary impairment. Both groups were similar in terms of sex, age, performance status, forced expiratory volume in one second (FEV1), tumour size, histology, grading, complication rate and follow-up duration. Segmentectomy was associated with a significantly better cancer-related 5-yr survival compared with wedge resection (71\% and $48 \%$, respectively). Local recurrence was significantly lower in segmentectomy $(16 \%)$ than in wedge resection $(55 \%)$. The same results were found when the population of patients with tumours $\leqslant 2 \mathrm{~cm}$ in diameter was analysed independently: 5-yr survival rates were $80 \%$ for segmentectomy and $48 \%$ for wedge resection. Local recurrence rates were $11 \%$ for segmentectomy and $40 \%$ for wedge resection. Although the mean number of resected lymph nodes differed (six in wedge resections and 12 in segmentectomies), in the multivariate analysis type of resection, age and tumour size were the only significant prognostic factors. Another study from the same institution [42] focusing on segmentectomy and on the location of the resected segments showed that local recurrence tended to be more frequent when 
segmentectomy was performed in segments $1-3$, compared with other segmental locations, and when resection margins are $\leqslant 1 \mathrm{~cm}$ in width. Additionally, the 5-yr survival rate of patients who underwent segmentectomy (63\%) was significantly lower than that of patients undergoing lobectomy $(83 \%)$. Local recurrence rates were also significantly different: $16 \%$ for segmentectomy and 5\% for lobectomy. When the selected group of patients with tumours $\leqslant 2 \mathrm{~cm}$ in diameter was analysed, differences in 5-yr survival rates for lobectomy (85\%) and segmentectomy $(68 \%)$ were not statistically significant. However, differences in local recurrence rate were significant: $2 \%$ for lobectomy and $12 \%$ for segmentectomy.

\section{Post-operative pulmonary function}

Although the most common indication of sublobar resection is impaired pulmonary function, its role in preserving pulmonary function post-operatively has seldom been studied. TAKIZAWA et al. [45] studied post-operative lung function in 40 patients who had undergone segmentectomy but who could otherwise have undergone lobectomy, and in 40 matched patients who had undergone lobectomy. Pre-operative forced vital capacity (FVC) and preoperative FEV1 were similar. Overall, 2 weeks postoperatively, FVC, as \% of pre-operative value, was significantly higher in the segmentectomy group $(72.7 \%$ versus $67.2 \%)$, but this advantage was not maintained at 12 months after the operation (94.9\% versus $91.0 \%)$. However, the significant benefit observed 2 weeks post-operatively in FEV1, as \% of pre-operative value, in the group of patients who had undergone segmentectomy $(73.0 \%$ versus $66.6 \%$ ) was maintained at 12 months (93.3\% versus $87.3 \%$ ). Although segmentectomy was associated with better postoperative lung function, the authors did not recommend it for good-risk patients because of the difficulties in identifying involved lymph nodes during the operation. The study of HARADA et al. [46] was also conducted in patients who could tolerate a lobectomy, but who were assigned to radical segmentectomy (38 patients) or lobectomy (45 patients) in a nonrandomised way after the patients had given their consent. In this study, FVC, FEV1 and anaerobic threshold were measured pre-operatively and at 2 and 6 months after the operation. In the segmentectomy group, the post-operative reduction of FVC and FEV1 was significantly smaller than in the lobectomy group, but there were no differences in the anaerobic threshold.

These two studies $[45,46]$ were performed in patients with good pre-operative pulmonary function. In patients with lung disease, careful evaluation of the type, degree and location of the lung abnormalities is important in order to select the best lung resection. This is particularly relevant in patients with emphysema of the upper lobes in whom a lobectomy will have a lung volume reduction effect, with improvement of postoperative lung function, whereas a segmentectomy would not achieve the same results [47]. Conversely, the preservation of lung function in patients with small lung cancers and anticipated long survival is important, considering the possibility of further lung resections to treat second primary lung tumours.

\section{Combined therapies}

Wedge resection of stage I tumours followed by external radiotherapy has already been tested, with heterogeneous results. In a study including 58 eligible patients, a mixture of benign and malignant lesions were wedge resected and the nonsmall cell lung cancers were post-operatively irradiated with 56 Gy if completely resected, or 66 Gy if incompletely resected [48]. It was found that clinical staging was inaccurate in $45 \%$ of cases, and that resection margins were positive in $6 \%$ of $\mathrm{T} 1$ and $23 \%$ of $\mathrm{T} 2$ tumours [48]. However, in a shorter series of six patients with T1N0M0 tumours who could not undergo lobectomy, wedge resection was followed by 40-50 Gy postoperative radiotherapy to the remnant lung besides the tumour and the hilum, and all patients survived $\geqslant 5$ yrs with no recurrence [49].

The combination of wedge resection and intraoperative brachytherapy is feasible with no added complications. VoYNOv et al. [50] treated 65 patients with stage IA and 45 with stage IB nonsmall cell lung cancer, who could not undergo lobectomy, with wedge resection and intra-operative application of ${ }^{125} \mathrm{I}$ Vicryl mesh over the stapler line and 2-cm margin. There were four recurrences only in the treated field, 13 regional recurrences and nine distant recurrences. The 5-yr local control, locoregional control, and overall survival rates were $90 \%, 61 \%$, and $18 \%$, respectively. Another study from the same institution [51] comparing sublobar resection and brachytherapy (41 patients) with lobectomy (126 patients) for stage IB nonsmall cell lung cancer found no differences in local recurrence $(4.8 \%$ for sublobar resections and $3.2 \%$ for lobectomies), disease-free survival $(43.0 \%$ for sublobar resection and $42.8 \%$ for lobectomies), and overall survival (54.1\% for sublobar resections and $51.8 \%$ for lobectomies). In the light of these results, the authors concluded that both treatments were equivalent and recommended the administration of brachytherapy whenever wedge resection had to be performed instead of lobectomy for stage IB tumours.

Intra-operative radiofrequency ablation immediately followed by wedge resection has also been applied to treat a small recurrent tumour in a patient who could not undergo anatomical resection [52]. Provided that the proper prospective studies are conducted, radiofrequency ablation could also be an adjuvant to sublobar resection for small lung cancers.

\section{THE SPECIAL CASE OF BRONCHIOLOALVEOLAR CARCINOMA}

Bronchioloalveolar carcinoma (BAC) is a subtype of adenocarcinoma that grows along alveolar structures without stromal, vascular or pleural invasion [53]. Pure BAC is at one end of the spectrum of adenocarcinoma (Noguchi types A, B, and C) and has an excellent prognosis because there are no invasive features and no lymph node involvement, while papillary adenocarcinoma with compressive and destructive growth is at the other end [54]. The World Health Organization recently tried to clarify the classification of adenocarcinomas [53]. The present review will focus on small BAC, pending a consensus between clinicians and pathologists, because there is still some confusion about noninvasive BAC and invasive adenocarcinoma with BAC features (an International Association for the Study of Lung Cancer/European Respiratory Society/ American Thoracic Society Task Force on lung adenocarcinoma: international multidisciplinary consensus subclassification, chaired by E. Brambilla and W. Travis, began work in October 2008). 
Small localised BACs may be detected by HRCT as pure GGO. Table 2 summarises the data from nine Japanese reports focused on the surgical treatment of small BACs, currently $\leqslant 2 \mathrm{~cm}$ in diameter or less, although two series include larger tumours [13, 55-62]. In most reports, these small BACs represent $<2 \%$ of the lung cancer series, and were treated by either lobectomy or sublobar resection. No nodal involvement was found. The 5 -yr survival rates were $100 \%$ in all but one of the series (in the other, a patient died from an unrelated cause) and there was no recurrence at follow-up.

When a GGO is found on HRCT, it is important to assess whether it is pure GGO or partly-solid GGO. While pure GGOs will be BACs or benign lesions, such as atypical adenomatous hyperplasia, partly-solid GGOs will have a component of invasive adenocarcinoma. The tumour disappearance rate on HRCT may also help in assessing the nature of the lesion. Most BACs have a tumour disappearance rate of $\geqslant 50 \%$ [63]. A recent report established the maximum standardised uptake value of positron emission tomography as an important tool in assessing the aggressive nature of adenocarcinomas $\leqslant 3 \mathrm{~cm}$ in diameter, in combination with the GGO ratio and tumour disappearance rate [64].

If a sublobar resection has been performed, the tumour must be studied intra-operatively by a frozen section to make sure that it is BAC and has no invasive adenocarcinoma component. In the trial reported by YOSHIDA et al. [61], this intra-operative assessment took $\sim 1 \mathrm{~h}$. There was agreement with the definitive post-operative pathological study in all specimens but one, which was changed from Noguchi's type B to C. However, other authors have reported difficulties in assessing the difference between BAC, atypical adenomatous hyperplasia, peripheral carcinoid tumours and other lesions [65]. If the intra-operative diagnosis of $\mathrm{BAC}$ is certain to the best of the pathologist's knowledge, then, according to the results of the series shown in table 2, a sublobar resection with no nodal dissection may be enough to ensure complete resection. Ongoing prospective trials in Japan and the USA [66] will have to confirm this strategy, and see whether systematic nodal dissection can be removed from the definition of complete resection in the case of this particular tumour. However, in case of doubt, lobectomy with systematic nodal dissection should be performed to ensure complete resection and adequate intra-operative staging [67].

\section{SUMMARY OF EVIDENCE AND RECOMMENDATIONS}

1) The results from the only randomised clinical trial comparing lobectomy with sublobar resections for T1N0 nonsmall cell lung cancer show that the latter are associated with higher local recurrence rates, but this study failed to show significant differences in overall and cancer-related survival (Level of evidence: $\mathrm{Ib}$ ). Therefore, in patients who can tolerate lobectomy, sublobar resections should be avoided (Grade of recommendation: A).

2) One meta-analysis, most retrospective studies, and a few prospective nonrandomised studies comparing lobectomy with sublobar resections for stage I nonsmall cell lung cancer, performed mainly in patients unfit for lobectomy but also in patients with adequate pulmonary function, show that the 5-yr survival rates are similar (Level of evidence: III). Therefore, in

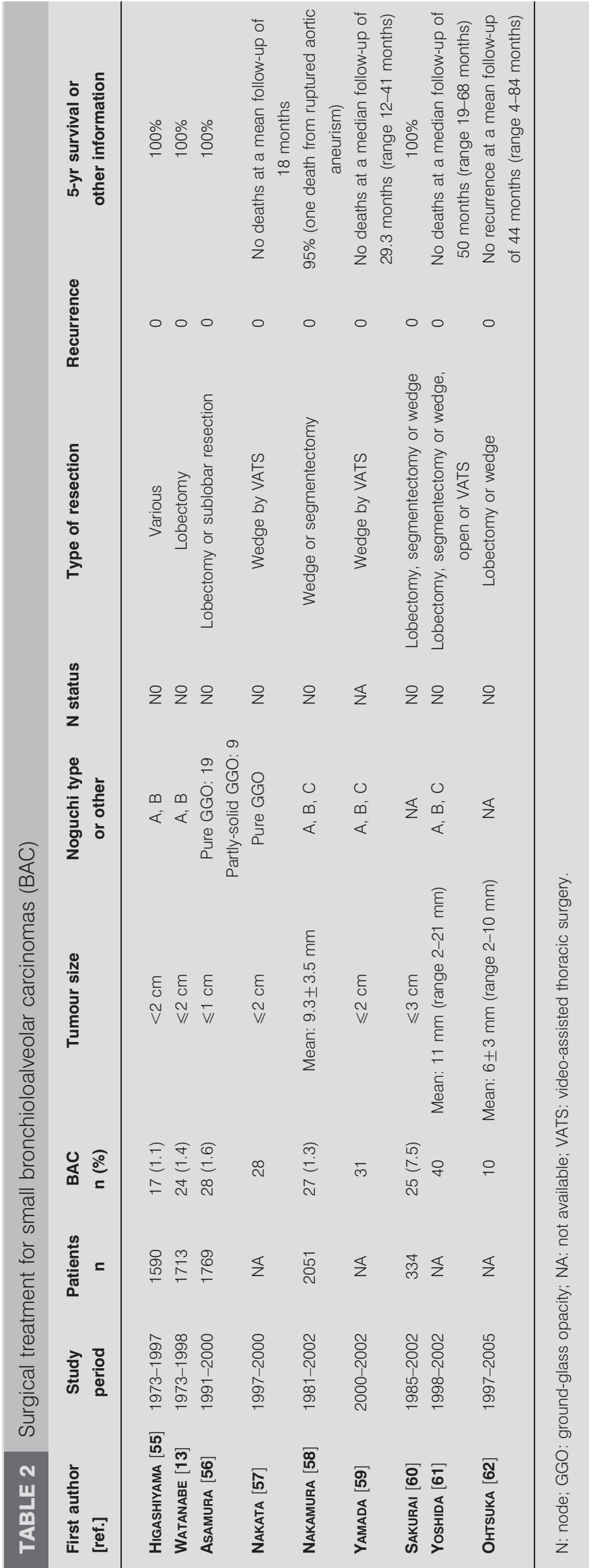


patients unable to undergo lobectomy, sublobar resection is an alternative that will confer similar prognosis (Degree of recommendation: $\mathrm{B}$ ).

3) When segmentectomy and wedge resections have been compared in retrospective studies, wedge resection is associated with worse survival and increased local recurrence (Level of evidence: III). Therefore, when a sublobar resection is the only resection a patient can tolerate, segmentectomy is a better choice than wedge resection (Degree of recommendation: B).

4) When tumour size has been analysed, it has been found that lobectomy and segmentectomy are equivalent for tumours $\leqslant 2 \mathrm{~cm}$ in diameter, but not for larger ones (Level of evidence: III). Therefore, segmentectomy should be reserved for tumours $\leqslant 2 \mathrm{~cm}$ in diameter; and lobectomy, for larger tumours, if possible (Degree of recommendation: B).

5) When patients' age has been considered, it has been found that, in terms of survival, lobectomy and wedge resection are equivalent in patients aged $>71 \mathrm{yrs}$, but lobectomy is associated with improved survival in younger patients (Level of evidence: III). Therefore, wedge resection should be reserved for patients aged $>71$ yrs (Degree of recommendation: B).

6) Wedge resections tend to have more resection margins $<1 \mathrm{~cm}$ in width than segmentectomies, and this has been associated with increased local recurrence (Level of evidence: III). Therefore, for both segmentectomies and wedge resections, resection margins should be $\geqslant 1 \mathrm{~cm}$ wide (Degree of recommendation: $\mathrm{B})$.

7) Post-operative radiotherapy or intraoperative brachytherapy may improve local control after wedge resection for nonsmall cell lung cancer (Level of evidence: III). Therefore, if wedge resection is the only resection the patient can tolerate, adjuvant radiotherapy seems advisable (Degree of recommendation: B).

8) Both lobectomy and sublobar resections for bronchioloalveolar carcinomas of $\leqslant 2 \mathrm{~cm}$ in diameter are associated with a 5 -yr survival rate of $100 \%$ and lack of recurrence (Level of evidence III). Therefore, if the intra-operative diagnosis of bronchioloalveolar carcinoma is certain, because of its noninvasive nature and lack of nodal involvement, sublobar resection with no systematic nodal dissection may be sufficient treatment for this particular type of tumour (Degree of recommendation: $\mathrm{B}$ ).

\section{REFERENCES}

1 Graham EA, Singer JJ. Successful removal of an entire lung for carcinoma of the bronchus. JAMA 1933; 101: 1371-1374.

2 Cahan WG, Watson WL, Pool JL. Radical pneumonectomy. J Thorac Surg 1951; 22: 449-473.

3 Cahan WG. Radical lobectomy. J Thorac Cardiovasc Surg 1960; 39: 555-572.

4 Jacobson MJ, Zand L, Fox RT, Lees W. A comparison of wedge and segmental resection of the lung. Thorax 1976; 31: 365-368.

5 Jensik RJ, Faber LP, Milloy FJ, Monson D. Segmental resection for lung cancer. A fifteen-year experience. J Thorac Cardiovasc Surg 1973; 66: 563-572.
6 Jensik RJ, Faber LP, Kittle CF. Segmental resection for bronchogenic carcinoma. Ann Thorac Surg 1979; 28: 475-483.

7 Weisberg D, Straehley CJ, Scully NM, Margulies DR. Less than lobar resections for bronchogenic carcinoma. Scand J Thor Cardiovasc Surg 1993; 27: 121-126.

8 Pastorino U, Valente M, Bedini V, Infante M, Tavecchio L, Ravasi G. Limited resection for stage I lung cancer. Eur J Surg Oncol 1991; 17: 42-46.

9 Lung Cancer Study Group, Ginsberg RJ, Rubinstein LV. Randomized trial of lobectomy versus limited resection for T1N0 non-small cell lung cancer. Ann Thorac Surg 1995; 60: 615-623.

10 Lederle FA. Lobectomy versus limited resection in T1N0 lung cancer. Ann Thorac Surg 1996; 62: 1249.

11 Rubinstein LV, Ginsberg RJ. Lobectomy versus limited resection in T1N0 lung cancer. Ann Thorac Surg 1996; 62: 1249-1250.

12 Nakamura H, Kawasaki N, Taguchi M, Kabasawa K. Survival following lobectomy ws limited resection for stage I lung cancer: a meta-analysis. Br J Cancer 2005; 92: 1033-1037.

13 Watanabe SI, Oda M, Tsunezuka Y, Ohta Y, Watanabe Y, Watanabe G. Should mediastinal nodal dissection be routinely undertaken in patients with peripheral smallsized ( $2 \mathrm{~cm}$ or less) lung cancer? Retrospective analysis of 225 patients. Eur J Cardiothorac Surg 2001; 20: 1007-1011.

14 Ikeda N, Hayashi A, Miura Y, et al. Present strategy of lung cancer screening and surgical management. Ann Thorac Cardiovasc Surg 2005; 11: 363-366.

15 Nakamura H, Kazuyuki S, Kawasaki N, Taguchi M, Kato H. History of limited resection for non-small cell lung cancer. Ann Thorac Cardiovasc Surg 2005; 11: 356-362.

16 Ketchedjian A, Daly B, Landreneau R, Fernando H. Sublobar resection for subcentimeter pulmonary nodule. Semin Thorac Cardiovasc Surg 2005; 17: 128-133.

17 Fields RC, Meyers BF. Sublobar resections for lung cancer. Semin Thorac Cardiovasc Surg 2006; 18: 85-91.

18 Pettiford BL, Schuchert MJ, Santos R, Landreneau RJ. Role of sublobar resection (segmentectomy and wedge resection) in the surgical management of non-small cell lung cancer. Thorac Surg Clin 2007; 17: 175-190.

19 Ginsberg RJ. Atlas of Clinical Oncology: Lung Cancer. Hamilton, BC Decker Inc, 2002.

20 Okada M, Yoshikawa K, Hatta T, Tsubota N. Is segmentectomy with lymph node assessment an alternative to lobectomy for non-small cell lung cancer of $2 \mathrm{~cm}$ or smaller? Ann Thorac Surg 2001; 71: 956-961.

21 Okada M, Nishio W, Sakamoto T, et al. Sleeve segmentectomy for non-small cell lung carcinoma. J Thorac Cardiovasc Surg 2004; 128: 420-424.

22 Shiraishi T, Shirakusa T, Iwasaki A, Hiratsuka M, Yamamoto S, Kawahara K. Video-assisted thoracoscopic surgery (VATS) segmentectomy for small peripheral lung cancer tumors. Surg Endos 2004; 18: 1657-1662.

23 Okada M, Mimura T, Ikegaki J, Katoh H, Itoh H, Tsubota N. A novel video-assisted anatomic segmentectomy technique: selective segmental inflation via bronchofiberoptic jet followed by cautery cutting. J Thorac Cardiovasc Surg 2007; 133: 753-758.

24 Atkins BZ, Harpole Jr DH, Mangum JH, Toloza EM, D'Amico TA, Burfeind Jr WR. Pulmonary segmentectomy by thoracotomy or thoracoscopy: reduced hospital length 
of stay with a minimally-invasive approach. Ann Thorac Surg 2007; 84: 1107-1113.

25 Warren WH, Faber LP. Segmentectomy versus lobectomy in patients with stage I pulmonary carcinoma. Five-year survival and patterns of intrathoracic recurrence. J Thorac Cardiovasc Surg 1994; 107: 1087-1094.

26 Kodama K, Doi O, Higashiyama M, Yokouchi H. Intentional limited resection for selected patients with T1N0M0 non-small cell lung cancer: a single-institution study. J Thorac Cardiovasc Surg 1997; 347-353.

27 Miller DL, Rowland CM, Deschamps C, Allen MS, Trastek VF, Pairolero PC. Surgical treatment of non-small cell lung cancer $1 \mathrm{~cm}$ or less in diameter. Ann Thorac Surg 2002; 73: 1545-1551.

28 Koike T, Yamato Y, Yoshiya K, Shimoyama T, Suzuki R. Intentional limited pulmonary resection for peripheral T1N0M0 small-sized lung cancer. J Thorac Cardiovasc Surg 2003; 125: 924-928.

29 Campione A, Ligabue T, Luzzi L, et al. Comparison between segmentectomy and larger resection of stage IA non-small cell lung carcinoma. J Cardiovasc Surg 2004; 45: $67-70$.

30 Mery CM, Pappas AN, Bueno R, et al. Similar long-term survival of elderly patients with non-small cell lung cancer treated with lobectomy or wedge resection within the Surveillance, Epidemiology, and End Results database. Chest 2005; 128: 237-245.

31 Martin-Ucar AE, Nakas A, Pilling JE, West KJ, Waller DA. A case-matched study of anatomical segmentectomy versus lobectomy for stage I lung cancer in high-risk patients. Eur J Cardiothorac Surg 2005; 27: 675-679.

32 Watanabe T, Okada A, Imakiire T, Koike T, Hirono T. Intentional limited resection for small peripheral lung cancer based on intraoperative pathologic exploration. Jpn J Thorac Cardiovasc Surg 2005; 53: 29-35.

33 Okada M, Nishio W, Sakamoto T, et al. Effect of tumor size on prognosis in patients with non-small cell lung cancer: the role of segmentectomy as a type of lesser resection. J Thorac Cardiovasc Surg 2005; 129: 87-93.

34 Griffin JP, Eastridge CE, Tolley EA, Pate JW. Wedge resection for non-small cell lung cancer in patients with pulmonary insufficiency: prospective ten-year survival. J Thorac Oncol 2006; 1: 960-964.

35 El-Sherif A, Gooding WE, Santos R, et al. Outcomes of sublobar resection versus lobectomy for stage I non-small cell lung cancer: a 13-year analysis. Ann Thorac Surg 2006; 82: 408-416.

36 Garzon JC, Ng CSH, Sihoe ADL, et al. Video-assisted thoracic surgery pulmonary resection for lung cancer in patients with poor lung function. Ann Thorac Surg 2006; 81: 1996-2003.

37 Okada M, Koike T, Higashiyama M, Yamato Y, Kodama K, Tsubota N. Radical sublobar resection for small-sized nonsmall cell lung cancer: a multicenter study. J Thorac Cardiovasc Surg 2006; 132: 769-775.

$38 \mathrm{Kraev}$ A, Rassias D, Vetto J, et al. Wedge resection vs lobectomy: 10-year survival in stage I primary lung cancer. Chest 2007; 131: 136-140.

39 Schuchert MJ, Pettiford BL, Keeley S, et al. Anatomic segmentectomy in the treatment of stage I non-small cell lung cancer. Ann Thorac Surg 2007; 84: 926-933.
40 Okumura M, Goto M, Ideguchi K, et al. Factors associated with outcome of segmentectomy for non-small cell lung cancer: long-term follow-up study at a single institution in Japan. Lung Cancer 2007; 58: 231-237.

41 Mondello B, Sibilio M, Pavone A, et al. "Intentionally" limited pulmonary resection versus lobectomy for the treatment of peripheral stage IA non-small cell lung cancers. G Chir 2007; 28: 7-12.

42 Sienel W, Stremmel C, Kirschbaum A, et al. Frequency of local recurrence following segmentectomy of stage IA nonsmall cell lung cancer is influenced by segment localisation and width of resection margins - implications for patient selection for segmentectomy. Eur J Cardiothorac Surg 2007; 31: 522-528.

43 El-Sherif A, Fernando HC, Santos R, et al. Margin and local recurrence after sublobar resection of non-small cell lung cancer. Ann Surg Oncol 2007; 14: 2400-2405.

44 Sienel W, Dango S, Kirschbaum A, et al. Sublobar resections in stage IA non-small cell lung cancer: segmentectomies result in significantly better cancer-related survival than wedge resections. Eur J Cardiothorac Surg 2008; 33: 728-734.

45 Takizawa T, Haga M, Yagi N, et al. Pulmonary function after segmentectomy for small peripheral carcinoma of the lung. J Thorac Cardiovasc Surg 1999; 118: 538-541.

46 Harada H, Okada M, Sakamoto T, Matsuoka H, Tsubota N. Functional advantage after radical segmentectomy versus lobectomy for lung cancer. Ann Thorac Surg 2005; 80: 20412045.

47 Santambrogio L, Nosotti M, Baisi A, Ronzoni G, Bellaviti N, Rosso L. Pulmonary lobectomy for lung cancer: a prospective study to compare patients with forced expiratory volume in $1 \mathrm{~s}$ more or less than $80 \%$ of predicted. Eur J Cardiothorac Surg 2001; 20: 684-687.

48 Shennib H, Bogart J, Herndon JE II, et al. Video-assisted wedge resection and local radiotherapy for peripheral lung cancer in high-risk patients: the Cancer and Leukemia Group B (CALGB) 9335, a phase II, multi-institutional cooperative group study. J Thorac Cardiovasc Surg 2005; 129: 813-818.

49 Kaneda M, Watanabe F, Tarukawa T, Tokui T, Sakai T. Limited operation for lung cancer in combination with postoperative radiation therapy. Ann Thorac Cardiovasc Surg 2007; 13: 15-20.

50 Voynov G, Heron DE, Lin CJ, et al. Intraoperative ${ }^{125} \mathrm{I}$ Vicryl mesh brachytherapy after sublobar resection for high-risk stage I non-small cell lung cancer. Brachytherapy 2005; 4: 278-285.

51 Birdas TJ, Koehler RPM, Colonias A, et al. Sublobar resection with brachytherapy versus lobectomy for stage Ib non-small cell lung cancer. Ann Thorac Surg 2006; 81: 434-439.

52 Fukuse T, Ogawa E, Chen F, Sakai H, Wada H. Limited surgery and radiofrequency ablation for recurrent lung cancer. Ann Thorac Surg 2006; 82: 1506-1508.

53 Colby TV, Noguchi M, Henschke C, et al. Adenocarcinoma. In: Travis WD, Brambilla E, Müller-Hermelink HK, Harris CC, eds. World Health Organization Classification of Tumours. Pathology and Genetics. Tumours of the Lung, Pleura, Thymus and Heart. Lyon, International Agency for Research on Cancer Press, 2004; pp. 35-44. 
54 Noguchi M, Morikawa A, Kawasaki M, et al. Small adenocarcinoma of the lung. Histologic characteristics and prognosis. Cancer 1995; 75: 2844-2852.

55 Higashiyama M, Kodama K, Yokouchi H, et al. Prognostic value of bronchiolo-alveolar carcinoma component of small lung adenocarcinoma. Ann Thorac Surg 1999; 68: 2069-2073.

56 Asamura H, Suzuki K, Watanabe SI, Matsumo Y, Maeshima A, Tsuchiya R. Clinicopathological study of resected subcentimeter lung cancers: a favorable prognosis for ground glass opacity lesions. Ann Thorac Surg 2003; 76: 1016-1022.

57 Nakata M, Sawada S, Saeki H, et al. Prospective study of thoracoscopic limited resection for ground-glass opacity selected by computed tomography. Ann Thorac Surg 2003; 75: 1601-1606.

58 Nakamura H, Saji H, Ogata A, Saijo T, Okada S, Kato H. Lung cancer patients showing pure ground-glass opacity on computed tomography are good candidates for wedge resection. Lung Cancer 2004; 44: 61-68.

59 Yamada S, Kohno T. Video-assisted thoracic surgery for pure ground-glass opacities $2 \mathrm{~cm}$ or less in diameter. Ann Thorac Surg 2004; 77: 1911-1915.

60 Sakurai H, Dobashi Y, Mizutani E, et al. Bronchioloalveolar carcinoma of the lung 3 centimeters or less in diameter: a prognosis assessment. Ann Thorac Surg 2004; 78: 17281733.
61 Yoshida J, Nagai K, Yokose T, et al. Limited resection trial for pulmonary ground-glass opacity nodules: fifty-case experience. J Thorac Cardiovasc Surg 2005; 129: 991-996.

62 Ohtsuka T, Watanabe K, Kaji M, Naruke T, Suemasu K. A clinicopathological study of resected pulmonary nodules with focal pure ground-glass opacity. Eur J Cardiothorac Surg 2006; 30: 160-163.

63 Nakayama H, Yamada K, Saito H, et al. Sublobar resection for patients with peripheral small adenocarcinomas of the lung: surgical outcome is associated with features on computed tomographic imaging. Ann Thorac Surg 2007; 84: 1675-1679.

64 Okada M, Tauchi S, Iwanaga K, et al. Associations among bronchioloalveolar carcinoma components, positron emission tomographic and computed tomographic findings, and malignant behaviour in small lung adenocarcinomas. J Thorac Cardiovasc Surg 2007; 133: 1448-1454.

65 Marchevsky AM, Changsri C, Gupta I, Fuller C, Houck W, McKenna Jr RJ. Frozen section diagnosis of small pulmonary nodules: accuracy and clinical implications. Ann Thorac Surg 2004; 78: 1755-1760.

66 Rusch VW, Tsuchiya R, Tsuboi M, Pass HI, Grunenwald D, Goldstraw P. Surgery for bronchioloalveolar carcinoma and "very early" adenocarcinoma: an evolving standard of care? J Thorac Oncol 2006; 1: Suppl. 9, s27-s31.

67 Rami-Porta R, Wittekind C, Goldstraw P. Complete resection in lung cancer surgery: proposed definition. Lung Cancer 2005; 49: 25-33. 